\title{
A INSERC̣ÃO DAS MÍDIAS AUDIOVISUAIS NO CONTEXTO ESCOLAR
}

\author{
Dostoiewski Mariatt de Oliveira Champangnatte* \\ Lina Cardoso Nunes**
}

RESUMO: O objetivo deste estudo foi avaliar como as mídias audiovisuais estão sendo utilizadas em salas de aula pelos professores de escolas públicas. Os participantes foram professores de três escolas municipais do Rio de Janeiro. Os dados foram coletados por meio de questionários, observações e entrevistas semiestruturadas, e submetidos à análise de conteúdo, modalidade temática. Os temas surgidos foram analisados a partir da literatura sobre mediações, mídia-educação e mídias. Os resultados apontam que a maioria dos professores considera importante o uso de mídias em sala de aula, mas que as usam apenas como recurso ilustrativo ou apoio em suas atividades.

Palavras-chave: Mídia-Educação. Mediações. Mídias.

\section{THE ENTRANCE OF AUDIOVISUAL MEDIAS IN THE SCHOOL CONTEXT}

ABSTRACT: The objective of this research is to appraise how audiovisual media is being used in classrooms by public schools teachers. Subjects are teachers of three municipal schools in Rio de Janeiro. Data were collected through questionnaires, observations and semi-structured interviews, and were analysed through content analysis, thematic mode. Based upon literature concerning to mediations, media and education, and media, themes which came out during our research were analysed. Results indicates that most teachers consider as important the act to use media during classes, but they use it only as support to their activities or as an illustration of classes' subject.

Keywords: Media-Education. Mediations. Media.

\footnotetext{
* Mestre em Educação pela Universidade Estácio de Sá (UNESA-RJ) e Professor do curso de Comunicação Social da Universidade do Grande Rio (UNIGRANRIO). E-mail: dostoiewskichampanhatte@gmail.com

* * Doutora em Educação pela Universidade Federal do Rio de Janeiro (UERJ) e Professora Titular da Universidade Estácio de Sá (UNESA-RJ). E-mail: nunes.lina@yahoo.com.br
} 


\section{INTRODUCุÃO}

A presença das mídias audiovisuais ${ }^{1}$ em sala de aula tem sido assunto de pesquisas e debates de diversos autores (MORAN, 2007; VALENTE, 2002; FANTIN, 2006; BELLONI, 2005). O interesse por esse tema aparece desde antes da implantação das políticas públicas para modernização das escolas, em estudos relacionados às mediações ${ }^{2}$, à mídia, à educação e à comunicação. Enfoca-se também a discussão de políticas públicas até estudos mais recentes que analisam a forma como essas políticas estão sendo aplicadas nas escolas e que tipos de resultados geraram.

Os estudos sobre as relações entre mídia e sociedade tiveram representatividade significativa na América Latina com as teorias latinoamericanas de comunicação e cultura, principalmente com a teoria latinoamericana das mediações de Martín-Barbero e com estudos do enfoque integral da audiência de Guillermo Orozco. Essas teorias partem de um ponto principal em que as mídias devem ser analisadas a partir de seus contextos sociais e históricos; e que cultura e sociedade devem ser pensadas como uma teia. A partir disso, analisar uma mídia audiovisual em determinado contexto, em sala de aula, em família ou em comunidade, implica perceber as mediações que ocorrem entre essa mídia e as pessoas que a cercam (MARTÍN-BARBERO, 2003; OROZCO, 1991).

Atentar para a realidade que cerca a escola é um dos primeiros passos para ficar em sintonia com a realidade e com os próprios alunos, que sofrem a todo momento interferências do mundo fora da escola. Trazer para a escola o que está em seu entorno pode ser uma das maneiras de aproximar essas duas realidades díspares, a de fora da escola e a da própria escola. Um exemplo disso é a incorporação das mídias no contexto escolar, o que tem sido observado tanto no uso da própria mídia em sala de aula como recurso pedagógico quanto por meio de discussões sobre as mídias e suas influências na sociedade. A mídia-educação estuda essas e outras relações referentes às mídias e à escola.

A mídia-educação possui diversas facetas, como aponta Fantin (2006), e a partir delas cria-se o que se pode chamar de uma educação com as mídias e de uma educação para as mídias. Equiparando-se com as facetas apresentadas por Belloni (2005), em que uma educação com as mídias refere-se ao uso da mídia como suporte para a didática em sala de aula, 
uma educação para as mídias seria a busca de se trabalhar na educação uma abordagem de leitura crítica e reflexiva das mídias, não só da mídia presente na escola, mas na sociedade como um todo.

Com relação a uma educação com as mídias, que se refere aos seus usos didáticos em salas de aula, tem-se observado nos espaços educacionais, em nossa vivência, em alguns casos, uma preocupação com a apropriação crítica das tecnologias pelos professores e alunos. Moran (2007) aponta que é interessante que o professor, a partir do trabalho com mídias, encontre meios de provocação para os alunos. Ao utilizar as tecnologias, seja para iniciar seja sintetizar um trabalho, o professor deve estar atento para incitar discussões em sala de aula, estimulando o interesse pelo tema abordado e gerando também a vontade de pesquisa nos alunos. É importante que o professor assuma a função de mediador, e não apenas de transmissor de um conhecimento.

Napolitano (2003), em trabalho sobre o uso de cinema em sala de aula, também aponta para a utilização crítica das mídias audiovisuais. $\mathrm{O}$ autor coloca que o cinema pode ser usado de diversas formas pelos professores, como fonte ou texto-gerador. A partir desses usos é interessante que o professor promova discussões e questionamentos sobre os conteúdos trazidos pelos filmes, comparando aos conteúdos de sala de aula, assim como com as realidades de seus alunos.

Trazer a mídia para dentro da escola, tanto para discussão quanto para seu uso pedagógico, é uma maneira de aproximar os alunos de suas realidades, o que permite maior facilidade na ocorrência das mediações escolares, tanto mediações alunos-professores quanto alunostecnologias-professores. (BELLONI, 2005; FANTIN, 2006). Mediações essas que, portanto, podem facilitar cada vez mais o ingresso e um trabalho crítico das tecnologias da informação e comunicação nos processos educacionais.

Os meios de comunicação promovem a descentralização na circulação dos saberes e a socialização a partir disso, colocando num mesmo espaço diversas culturas, padrões e visões de mundo (MARTÍN-BARBERO, 2003). Assim a escola tem de estar atenta a essas transformações para participar desse processo,

(...) interagir com as mudanças no campo/mercado profissional, ou seja, com as novas figuras e modalidades que o ambiente informacional possibilita, com os discursos e relatos que os meios de comunicação de massa mobilizam e 
com as novas formas de participação cidadã que eles abrem, especialmente na vida local (MARTÍN-BARBERO, 2003, p. 67).

Atentar para a realidade que a cerca é um dos primeiros passos para a escola ficar em sintonia com a realidade e com os próprios alunos, que sofrem a todo momento interferências do mundo fora da escola. Trazer para a escola o que está em seu entorno pode ser uma das maneiras de aproximar essas duas realidades díspares, a de fora da escola e a da própria escola. Um exemplo disso é por meio da incorporação das mídias no contexto escolar, tanto no uso da própria mídia em sala de aula como recurso pedagógico quanto por meio de discussões sobre as mídias e suas influências na sociedade, tendo em vista que a mídia-educação estuda essas e outras relações referentes às mídias e a escola.

A teoria das mediações influenciou diversos estudos sobre mídia-educação, principalmente na maneira de se perceber as relações dialéticas entre o meio e a sociedade que o cerca, no caso, o contexto escolar. Ainda remetendo a Martín-Barbero (2003, p. 67), "a escola deve interagir com os campos de experiência onde se processam hoje as mudanças". Isso inclui desde as relações da ciência com a arte, das literaturas escritas e audiovisuais, até mesmo em questões de pesquisa e experimentações estéticas. Assim, é importante que a escola esteja atenta às mediações ocorridas entre a família e o mundo que a cerca, pois o aluno faz parte do contexto familiar. De acordo com Martín-Barbero e Rey (apud OROFINO, 2005), a família é um ambiente de grandes tensões e, ao mesmo tempo, é onde o indivíduo encontra ambiente de expressão e/ou de repressão. É a unidade básica no meio do qual formam suas primeiras impressões. Assim como a escola, a família também está sujeita às mediações das mídias, reforçando a concepção de uma análise da realidade como uma teia. Dessa forma, perceber as mídias inseridas no contexto escolar é perceber qual realidade cerca essa própria mídia dentro da escola, de que maneira é administrada e de que forma a presença dela altera o cotidiano escolar.

Como já dito, a mídia-educação ocupa-se das análises das relações entre a mídia e a escola e, em seus estudos, aborda aspectos sobre educação e comunicação. As discussões em torno da mídia-educação envolvem também a própria definição desse termo e seus campos de estudo. Belloni (2005) faz um estudo sobre os aspectos conceituais e históri- 
cos da mídia-educação e aponta duas facetas que ela possui: a de ser uma ferramenta pedagógica e também a de ser um objeto de estudo complexo e multifacetado, que permeia a realidade, ou seja, a primeira faceta refere-se à mídia utilizada dentro da sala de aula (como recurso pedagógico) e a segunda, à mídia fora da sala de aula (TV, rádio, cinema, internet). Porém, em ambos os casos, apesar de terem duas facetas diferentes, se interligam em diversas análises, podendo formar também um objeto único de estudo.

A presença das mídias nas escolas públicas brasileiras é influenciada por diversas políticas governamentais. O governo federal criou, na década de 1990, três iniciativas principais: a TV Escola, o DVD Escola e o ProInfo. O projeto TV Escola consistiu na criação de um canal de televisão em que seriam exibidos programas educativos. Foram comprados e enviados para as escolas aparelhos e fitas de videocassete, televisões e antenas parabólicas. Algumas escolas não receberam o kit da TV Escola e, mais recentemente, integraram o projeto DVD Escola. Este projeto consiste no envio de aparelhos de DVD e de uma caixa contendo DVDs com os principais programas da TV Escola, abrangendo diversos conteúdos e disciplinas (BRASIL, 2009).

Em 1997, foi criado o ProInfo, que consistiu na construção de laboratórios de informática em diversas escolas públicas do país. As escolas deveriam ser equipadas com computadores com acesso à internet. Paralelo à criação do ProInfo foi criado o NTE (Núcleo de Tecnologia Educacional), em que são reunidos educadores e especialistas em informática para dar suporte funcional e educativo às escolas.

Com relação às iniciativas municipais, a Secretaria Municipal de Educação do Rio de Janeiro realiza o projeto Sala de Leitura, o Programa Informática Educativa e a Multirio. O projeto Sala de Leitura prevê que, nas escolas municipais, haja uma sala onde existam livros, vídeos educativos, filmes, televisão, aparelho de DVD e vídeo, jornais e revistas. O Programa Informática Educativa prevê a instalação de laboratórios de informática com acesso à internet nas escolas onde ainda não houve o benefício do ProInfo. Há também a Multirio, que é uma empresa vinculada à SME-RJ e que exibe, produz e distribui conteúdos educativos para as escolas da rede municipal (SME-RJ, 2009; MULTIRIO, 2009).

Diante desse quadro de modernização das escolas públicas brasileiras e a partir de estudos referentes à mídia-educação e mediações é que se propõe este artigo, voltado para a análise de como as mídias audio- 
visuais implantadas em escolas municipais do Rio de Janeiro estão sendo usadas em termos didático-pedagógicos, tendo em vista a perspectiva das mediações.

Esta pesquisa teve por objetivo geral investigar como as mídias audiovisuais implantadas pelo governo em escolas públicas estão sendo utilizadas em sala de aula. Nesta pesquisa, as mídias audiovisuais focalizadas foram o computador/internet e os vídeos/DVDs utilizados em sala de aula.

De acordo com os aspectos apresentados, os procedimentos metodológicos que orientaram a presente pesquisa foram os da abordagem qualitativa (ALVES-MAZZOTTI; GEWANDSZNAJDER, 2000; BOGDAN; BIKLEN, 1994). A pesquisa baseou-se no acompanhamento direto e prolongado, por parte do pesquisador, da realidade pesquisada, obtendo descrições detalhadas dos fatos, dos sujeitos e suas atitudes, assim como de trechos de documentos, relatórios e materiais escritos pertencentes ao campo estudado.

Os sujeitos da presente pesquisa foram professores de três escolas da Rede Municipal de Ensino do Rio de Janeiro, pertencentes à $2^{\mathrm{a}}$ Coordenadoria Regional de Educação (CRE), denominadas neste estudo como Escolas A, B e C. A escolha dessas escolas se deu por questões de facilidades de acesso ao campo de pesquisa. A primeira etapa da pesquisa consistiu numa fase exploratória, de visitas às escolas para a apresentação da pesquisa aos coordenadores, diretores e professores, e também para o conhecimento preliminar do espaço escolar. Ao final desse período, foi feita a caracterização dos participantes da pesquisa por meio da aplicação de um questionário a 20 professores. Após a aplicação do questionário e a consulta aos participantes sobre a possibilidade de suas aulas serem observadas, foram definidos dez professores para o início das observações. Durante esse período, foi elaborado um diário de campo e, ao final do período de observação, foram realizadas entrevistas semiestruturadas com os professores observados.

Para este artigo foram destacados os resultados das entrevistas semiestruturadas, sendo que a análise dos dados relativa às falas dos participantes privilegiou a análise de conteúdo, na modalidade temática (BARDIN, 2003). A partir dessa técnica, realizou-se leitura exaustiva das entrevistas e foi feita a contagem de vários itens de significados, chegando-se a uma unidade de significação de determinado bloco analisado. As 
fases da análise de conteúdo organizaram-se segundo três aspectos: a préanálise, a exploração do material e o tratamento dos resultados. No item 3 são apresentados os resultados relativos à análise.

\section{0 CAMPO DE PESQUISA}

\subsection{Breve descrição do campo}

A caracterização das escolas foi feita a partir de observações e de informações pesquisadas junto aos funcionários e visou a apresentar a realidade estrutural das mesmas, principalmente no que se relaciona à presença das mídias nessas escolas.

As três escolas possuem laboratório de informática com dez computadores, sendo que nem todos funcionavam satisfatoriamente durante a realização da pesquisa. As escolas $\mathrm{B}$ e $\mathrm{C}$ possuíam as salas de leitura em funcionamento, ao contrário da escola $\mathrm{A}$, em que a sala de leitura estava em reforma. Todas as escolas possuíam sala de vídeo. As escolas B e C possuíam sistema de tabela de agendamento de uso da sala de vídeo e da informática, enquanto que na escola $\mathrm{C}$ o agendamento era feito apenas de forma oral com a coordenação.

\subsection{Características dos professores}

As características dos professores foram traçadas a partir da aplicação de um questionário fechado, que se compunha de uma parte sobre tempo de trabalho, carga horária e formação profissional e outra parte que esclarecia questões sobre a utilização das mídias. Foram escolhidos aleatoriamente 20 professores de cada escola, que responderam às perguntas sem a interferência do pesquisador.

\section{ANÁLISE DOS DADOS COLETADOS}

A partir da análise dos dados coletados relacionados às falas dos participantes foi elaborado um quadro de temas e subtemas emergentes das entrevistas semiestruturadas aos dez professores que se dispuseram a 
participar do estudo e dos diários de campo. Os principais temas e subtemas surgidos serão apresentados a seguir, juntamente com depoimentos dos professores e referências aos autores escolhidos para fundamentar a investigação.

TEMAS

SUBTEMAS

\begin{tabular}{|c|c|}
\hline $\begin{array}{l}\text { 3.1 A IMPORTÂNCIA DO USO DE } \\
\text { MÍDIAS EM SALA DE AULA }\end{array}$ & $\begin{array}{l}\text { 3.1.1 A mídia como aproximação da realidade do aluno } \\
\text { 3.1.2 A mídia como uma nova linguagem e o processo } \\
\text { ensino-aprendizagem }\end{array}$ \\
\hline 3.2 UT & 3.2.1 Utilização de vídeos em sala de aula \\
\hline E INTERNET EM SALA DE AULA & $\begin{array}{c}\text { 3.2.2 Utilização da internet em sala de aula } \\
\text { 3.2.3 A sala de Leitura }\end{array}$ \\
\hline 3.3 DIFICULDADES DO USO & 3.3.1 Infraestrutura das escolas e seus usos \\
\hline DE VÍDEO E INTERNET NAS ESCOLAS & $\begin{array}{l}\text { 3.3.2 Características e comportamentos dos } \\
\text { professores perante as mídias } \\
\text { 3.3.3 } 0 \text { professor de laboratório de informática }\end{array}$ \\
\hline $\begin{array}{c}\text { 3.4 MÍDIAS E POSSIBILIDADES } \\
\text { DE MEDIAÇ̃̃ES }\end{array}$ & $\begin{array}{l}\text { 3.4.1 Mediaç̃ões e o trabalho aprofundado com mídias } \\
\text { 3.4.2 Mediações e o trabalho com mídias } \\
\text { como ilustrativo }\end{array}$ \\
\hline
\end{tabular}

Os professores foram questionados sobre a importância que veem no uso de mídias em sala de aula e apresentaram diversos pontos de vista referentes às mídias no contexto escolar. Esses pontos foram agrupados em dois blocos, que se referem à mídia como aproximação da realidade do aluno e à mídia como uma nova linguagem e suas implicações no processo ensino-aprendizagem.

\subsubsection{A mídia como aproximação da realidade do aluno}

Diante do questionamento sobre a importância do uso de mídias em sala de aula alguns professores levantaram a questão de que as mídias na escola aproximam os alunos da realidade. A seguir, algumas falas de professores sobre esse ponto

P.B.9 - a mídia, ela é importante primeiro porque está dentro da realidade deles, no dia a dia eles já usam televisão, internet, DVD, vídeo. Então é aproximar a escola, aproximar o ensino da realidade deles. E dar a possibilidade de novidades, de coisas mais interessantes.

P.C.5 - Inicialmente eu acho que os alunos vivem de forma multimidia, estão cercados de midia e a escola tem que acompanhar... por isso que a escola precisa usar as mídias, se não 
ela estará deslocada da vida do aluno... hoje em dia, professor que vive só de giž quadro e livro não consegue acompanhar o ritmo do aluno!

P.A.10 - Eu acho que é importante pelo pé que a gente tem com a realidade. A gente pode aproveitar as midias e as coisas que eles vivem para trabalhar questões ligadas às realidades deles! Esses meninos vivem em lan houses o tempo todo! Se não tão na lan house, estão vendo televisão, vendo DVD, que está tão barato nas ruas!... Eu procuro fazer essa ponte, trabalhar com as midias para aproximar o trabalho aqui na escola com o que eles vivem lá fora.

Os professores apontam que os alunos fora da escola vivem cercados das mídias e as utilizam e que, por isso, a escola deve também utilizá-las, tanto para aproximar-se da realidade de seus alunos quanto para não ficar para trás no que diz respeito aos avanços tecnológicos. Aponta Martín-Barbero (2004) que a escola precisa se ambientar com a realidade e com os avanços dos meios de comunicação, e deve procurar se relacionar com a realidade que a cerca, que é permeada por tecnologias que se renovam contínua e rapidamente. Caso isso não ocorra, a escola pode ficar para trás em termos tecnológicos, e isso se refletirá também nas suas relações com seus alunos, que já estarão acostumados a novos modos de relacionamentos, advindos das tecnologias, e que poderão achar obsoletas as formas como a escola conduz suas relações com os alunos.

\subsubsection{A mídia como uma nova linguagem e o processo ensino-aprendizagem}

Um segundo ponto que os professores abordaram com relação à importância do uso de mídias está relacionado ao fato de eles perceberem a mídia como uma nova linguagem em sala de aula, e que isso é muito importante e pode, positivamente, ser aproveitado pelos professores, o que possibilita mudanças no processo ensino-aprendizagem. Entre alguns depoimentos estão

P.B.4 - As mídias são novas linguagens, a gente vive num mundo de novas linguagens e quanto mais linguagens você trabalhar para que alguém encontre um caminho para entender uma coisa é fundamental... Eu procuro trabalhar o mesmo assunto das mais diferentes maneiras para que cada aluno encontre a sua maneira de aprendizagem. E o vídeo e a internet são mais outras linguagens para os alunos aprenderem. Se não entendeu com o giz. e o livro, talvez possa entender de outra maneira!

P.A.5 - Olha, en acho que traz muitos benefícios para os alunos em termos de conteúdo, em termos de outra linguagem que possibilita melhor aprendizado. Às vezes um aluno não 
consegue entender o conteúdo com a explicação do professor e daí com o vídeo ou em um jogo na internet ele aprende mais fácil.

Partindo para uma análise desses depoimentos, remete-se a Orozco (2002), que aponta que as novas tecnologias devem servir à educação como uma nova linguagem e para o aproveitamento de diversas linguagens e formatos. Como as mídias são formatos diferentes de um livro ou de um quadro-negro com giz, ou seja, da linguagem escrita e ou mesmo falada, como a fala do professor, elas também devem ser encaradas como uma nova linguagem em sala de aula, ou seja, devem ser analisadas não só pelos parâmetros da linguagem escrita. Um texto de vídeo (cinematográfico) possui uma linguagem diferente de um texto escrito e mesmo até de seu roteiro escrito. Há diversas informações que precisam ser observadas, como o cenário, a iluminação, o figurino, a interpretação dos atores, a direção, fatores que, juntos, formam a linguagem do vídeo e que assim permitem seu entendimento. Uma análise que contemple apenas as falas ou a narrativa de um vídeo ficará muito aquém das possibilidades oferecidas pela própria linguagem peculiar do vídeo.

\subsection{UTILIZAÇÃO DE VÍDEOS E INTERNET EM SALA DE AULA}

Quanto à utilização dessas mídias, surgiram dois subtemas que estão apresentados a seguir.

\subsubsection{Utilização de vídeos em sala de aula}

P.B.3 - Eu geralmente uso o vídeo na introdução de um novo conteúdo, de um novo assunto. Daí, no decorrer do processo, posso também usar novamente o vídeo para melhorar a noção, exemplificar melhor a teoria, ilustrar.

P.A.3 - Eu, quando passo vídeo para meus alunos, sempre passo vendo o vídeo e parando. Vamos vendo o vídeo e vamos discutindo, eu vou explicando pra eles o que está acontecendo e eles também vão me perguntando. Se eu passo o vídeo de uma vez, eles não vão prestar atenção, não vão entender. E, quando acabar o vídeo, vão ter esquecido o comeşo da história! Vendo e parando dá pra ter mais controle de que o vídeo realmente está sendo útil.. Porque depois, nas outras aulas, eu acabo me referindo ao vídeo.

P.B.7 - Eu fiz lançamento de noção com o filme, eu apresentei mais conteúdos com os textos, as gravuras e a pesquisa na internet após o filme, eu dei a eles base pra eles poderem 
criar suas historinhas. E como todas tinham que ter a ver com a familia real... o que eles fizeram? Prestaram atenção ao conteúdo dado, aprenderam a matéria pra contar a história! Isso foi muito bom!

O primeiro depoimento refere-se ao uso do vídeo em sala de aula como ilustrativo, o que remete ao trabalho de Pretto (1996), Moran (2000) e Napolitano (2003). Todos esses autores classificam o tipo de uso ilustrativo como uma espécie de subaproveitamento das potencialidades do uso do vídeo em sala de aula. A partir da análise das observações e também de outros depoimentos, nota-se que o uso do vídeo como ilustrativo predominou entre a maioria dos professores das escolas observadas. O segundo depoimento se assemelha ao uso do vídeo como sensibilização, uma das sugestões de uso de vídeo em sala de aula apontadas por Moran (2000). A sensibilização consiste em usar o vídeo para iniciar determinado conteúdo, apresentando-o com a finalidade de gerar ainda mais interesse. $\mathrm{O}$ terceiro depoimento refere-se ao vídeo ser exibido e, durante a sua exibição, professores e alunos discutirem sobre ele. Napolitano (2003) classifica esse tipo de análise como uma análise em conjunto de um vídeo como fonte ocorrendo, portanto um trabalho mais aprofundado com o vídeo.

\subsubsection{Utilização da internet em sala de aula}

Esse subtema explicita a forma como os professores utilizam a internet na prática pedagógica, conforme se evidencia nas falas a seguir:

P.A.1 - Eu vejo que a internet interessa muito a eles, eles ficaram interessados no conteúdo, perguntaram, trocaram informações com os colegas, assimilaram o conteúdo. Acho que isso é muito importante, porque fica até mais fácil pra a gente trabalbar um conteúdo, porque a vontade está partindo deles também. E isso se reflete aqui na sala de aula, depois do vídeo, da internet, de saberem do que se trata o assunto, eles assimilam muito melhor o que leem no livro.

P.B.7 - A Internet deixa os alunos muito à vontade. E aí eu aproveito isso para trabalhar os conteúdos. Eles se interessam muito porque estão vendo ali diversas informações, não sou só eu que estou falando. E aprendem bem mais. E o interessante também é que não se contentam só com uma informação de um site, vão em outro, em outro. O interesse deles é fascinante quando os levo pra internet.

P.A.6 - O material que os alunos trazem da internet serve como um complemento do que eu trabalho em sala de aula... Eles pesquisam, copiam, colam no caderno, daí fica como um 
complemento para eles mesmos... O conteúdo em si eu trabalho é em sala de aula, a partir do livro.

Os dois primeiros depoimentos referem-se ao interesse dos alunos com relação à internet. Sobre esse ponto, Romero (2006) e Valente (2002) colocam que a informática e, em especial, a internet podem despertar o aluno para determinado conteúdo de forma mais concisa. Devido à sua questão multimídia, a internet disponibiliza imagens, textos ilustrados, vídeos que podem facilitar a assimilação do aluno.

Já o terceiro depoimento mostra as maneiras de realização de pesquisa pelos alunos na internet, caracterizada somente por uma visão ilustrativa do processo. Primo (2006) coloca que a internet, quando usada para pesquisas sem um diálogo ou discussão, a partir do que está sendo pesquisado, se parece bastante com as posturas assumidas diante das pesquisas com enciclopédias. Quando os alunos copiam textos da internet, ou mesmo imprimem e colam no caderno, sem os professores discuti-los ou questioná-los, é uma postura semelhante à que era realizada anteriormente. Essa é uma postura de subaproveitamento dos recursos da internet, além de uma perpetuação da cultura de transmissão de conhecimento em vez da construção conjunta. O problema não está na consulta de textos na internet, mas na não utilização desses textos apreendidos para gerar discussões, debates e questionamentos (PRIMO, 2006; MORAN, 2000).

\subsection{DIFICULDADES DO USO DE VÍDEO E INTERNET NAS ESCOLAS}

Esse tema mostra as dificuldades sentidas pelos entrevistados tanto em relação à infraestrutura quanto às características dos professores e à necessidade de um professor no laboratório de informática.

\subsubsection{Infraestrutura das escolas e seus usos}

A seguir, apresentam-se alguns trechos de depoimentos transcritos:

P.A.4 - Com relação ao vídeo, aqui na escola tem problema com sala. Por exemplo, esses dias en estava tendo reunião de Bolsa Família na sala de vídeo no horário de aula; com tantas salas pra usar foram usar logo a de vídeo e não iam passar vídeo. Falta um pouco 
de organização nesse sentido. Tipo também na sala de informática, que funciona xérox lá também... Você está com os alunos na internet, ai entra alguém pra tirar xérox, isso desconcentra o teu trabalho.

P.C.7 - Eu acho que eu poderia até usar mais as mídias do que eu uso. E não faço isso porque é muito trabalhoso trabalhar midia em escola pública. Toda hora você tem um problema com equipamento, os equipamentos são precários! E aí você perde o controle da sala quando um equipamento estraga e você tem que parar pra arrumar, se é que você sabe arrumar ou mesmo tem que saber arrumar aquele equipamento.

Os depoimentos mostram algumas das dificuldades encontradas pelos professores quanto à utilização das mídias nas escolas em termos de infraestrutura. Napolitano (2003) coloca a questão dos equipamentos quebrados ou em mau estado como um empecilho à fluidez do trabalho do professor com o vídeo na escola, pois isso pode acabar sendo fator de desinteresse do professor em buscar a mídia, pois ele sabe que terá problemas com o equipamento. Também pode ser um fator que contribui para a dispersão dos alunos, o que pode comprometer o trabalho que o professor pretende desenvolver.

\subsubsection{Características e comportamentos dos professores diante das mídias}

Assim se pronunciaram os professores sobre esse subtema:

P.B.5 - Olha, uma das dificuldades que eu sinto, e que eu também vejo nos outros professores para trabalhar midias aqui na escola, é que a maioria dos professores não tem tempo para preparar atividades com mídias! Todo mundo dá aula em outras escolas, seja em particular ou mesmo da prefeitura, com uma segunda matrícula... E também não acabam tendo tempo de fazer esses cursos de aperfeiçoamento que a Secretaria oferece! Eu mesmo tinha muita vontade de fazer, de aprender a mexer mais com computador! Mas não tenho tempo, dou aula em quatro escolas!

P.C.9 - Professor que não sabe mexer com internet não mexe não! Mas também não se deve culpar esse professor por não usar a internet! Se ele não teve formação, como exigir dele que ele saiba? Seria interessante que os professores fizessem cursos, mas acabam não tendo tempo! Ou que tivessem aprendido em suas formacões como utilizar essas midias, né!

Esses dois depoimentos levantam alguns dados quanto às características dos professores. O primeiro dado refere-se à carga horária semanal. A partir dos dados da caracterização do campo, nota-se que a maioria dos professores possui carga horária alta. Kenski (2003) afirma que devem ser consideradas, nos projetos pedagógicos, questões que per- 
meiam essa realidade de grandes cargas horárias dos professores, em termos pedagógicos e político-econômicos, pois isso interfere no desempenho em sala de aula. O outro dado refere-se à formação do professor para o trabalho com mídias. Hargreaves (2004) afirma que é importante que os cursos de formação de professores busquem, dentro de suas grades, abranger disciplinas que envolvam as tecnologias. Assim, os professores teriam uma base dentro da própria graduação sobre o trabalho com as tecnologias, precisando futuramente apenas se aperfeiçoar e atualizar.

\subsubsection{Professor responsável pelo laboratório de informática}

Nem o ProInfo nem o Programa Informática Educativa da SME-RJ preveem em seus projetos e programas um professor ou um funcionário que seja responsável somente pelo laboratório de informática, como há o professor regente de sala de leitura (MEC, PROINFO, SME, 2009). Apesar disso, alguns professores citaram, nos depoimentos, como dificuldades ao uso da internet em sala de aula a falta de um professor responsável pelo laboratório de informática.

P.B.10 - É impossivel manter disciplina com uma sala onde tem três alunos por computador. Se tivesse alguém responsável pela informática facilitaria mais. Não só nisso, mas pra sugerir atividades também... Eu não me deixava abalar muito por isso não, mas vai cansando sabe... Cada dia estou indo menos para informática por causa disso...

\subsection{MÍDIAS E POSSIBILIDADES DE MEDIAC̣ÕES}

\subsubsection{Mediações e o trabalho com mídias}

Alguns professores apresentaram um trabalho mais aprofundado com as mídias, aproveitando diversas potencialidades, promovendo discussões e questionamentos a partir dos conteúdos apresentados. Foi observado que, a partir desse tipo de trabalho, as possibilidades de mediações foram muitas.

P.A.1 - As mídias ajudam na mediação professor-aluno. Mas não adianta trabalbar as midias com um fim em si mesmas. A ferramenta deve ser usada como meio, ai sim ela deve fazer a mediação, ai sim podemos tirar coisas proveitosas daí.

P.C.8 - Eu escuto muito os alunos, eu sou mais uma mediadora, como eu acho que este tipo de trabalho tem que ser mesmo... As midias trazem para os alunos uma possibilida- 
de que permeia o seu cotidiano e isso facilita o meu trabalbo, como ele está mais interessado, o meu trabalho é facilitado...

De acordo com os depoimentos, nota-se a relação entre as mediações ocorridas em sala de aula e o modo do trabalho dos professores com as mídias, de maneira articulada. Agregando-se os relatos dos diários de campo das observações desses dois professores, as diversas categorias de mediações apontadas por Orozco (1991) puderam ser notadas.

\subsubsection{Mediações e o trabalho com mídias como ilustrativo}

No decorrer da análise dos depoimentos e das observações sobre as mediações, foi possível constatar que muitos professores atribuíram papel importante à questão das mediações a partir das mídias, mas que, durante seus trabalhos, conduziram atividades de certa maneira que vão de encontro ao que afirmaram. Os professores utilizaram as mídias como recurso ilustrativo aos conteúdos que trabalhavam, servindo apenas como complemento às atividades, sem gerar discussões e questionamentos, prejudicando as possibilidades de mediações com o uso das mídias. Para iniciar essa análise, seguem alguns trechos de depoimentos

P.A.4 - Eu acho que as mediações são muitas. As mídias trazem novos assuntos, expandem os conbecimentos do professor também e, claro, melhoram o ritmo da aula, provocam discussões, questionamentos, aumentam as participações dos alunos. Até melhoram a disciplina, sabia...

P.B.10 - Eu acho que as mídias mediam muito professor e aluno. Elas trazem novas realidades, novos assuntos e acham que mediam mais que os livros, porque é mais dinâmico. Eu noto isso e os alunos também. Eles também se sentem motivados e até eles trazem novas situaçoes para as aulas, como novos sites para trabalharmos jogos, até mesmo educativos.

Durante as observações notou-se que o professor P.A.4 trabalhou um vídeo-documentário sobre lixo (DVD Escola) e depois levou os alunos para a internet para pesquisar sobre reciclagem de lixo. Durante e após o trabalho com as mídias, o professor não provocou muitas discussões e sempre tratou o conteúdo proveniente das mídias como ilustrativo do conteúdo que estavam vendo no livro didático. Os alunos assistiram passivos ao vídeo e também foram pesquisadores passivos na internet. Durante e após o uso das mídias, foi observado que não surgiram muitas discussões e diálogos dos alunos com o professor sobre os conteúdos vis- 
tos, ou seja, as possibilidades de mediações com o uso das mídias foram prejudicadas. É curioso notar que o depoimento do professor P.A.4 vai de encontro ao que ele aponta sobre mediações.

O professor P.B.10 também realizou seu trabalho com as mídias utilizando-as de forma ilustrativa, sem questionar a própria mídia com os alunos e sem provocar discussões a respeito dela. O professor passou um vídeo sobre sistema circulatório humano (documentário do DVD Escola) e, depois do vídeo, voltou-se para o livro didático com os alunos. Em alguns momentos, o professor remetia ao vídeo, mas para ilustrar o que estava falando, sem abrir muitos espaços para os alunos falarem do que viram. Dessa forma, as possibilidades de mediações com o uso das mídias também foram prejudicadas. Foi observado que o professor P.B.10, em seu depoimento, tem uma opinião que vai de encontro ao que foi observado em seu trabalho.

Em relação a essa forma de uso apenas ilustrativo das mídias, pode-se afirmar, a partir de Martín-Barbero (2003), que as mediações não estariam ocorrendo de forma adequada, pois não sofrem influências de todos os participantes da teia, predominando a mediação institucional professor-aluno, excluindo as mediações individuais e situacionais, ocorrendo, nesse sentido, de maneira pobre, a mediação vídeo-tecnológica (OROZCO, 1991). Essa forma ilustrativa de tratar a mídia em sala de aula não aproveita todas as potencialidades que as mídias podem ter no trabalho pedagógico, portanto não se estão valorizando as possibilidades de mediações que podem ocorrer em sua utilização.

Napolitano (2003) e Moran (2007) colocam que é importante que o professor procure mediar relações de conteúdo/linguagem de um filme com o conteúdo escolar, procurando também estimular os alunos a identificar os assuntos dos filmes com suas realidades. Dessa forma, o professor pode ser realmente um mediador em sala de aula, deixando de ser um transmissor de conteúdo, mesmo que esse conteúdo esteja sendo passado através de um vídeo. Se esse vídeo for visto apenas como ilustrativo e não suscitar discussões pelo professor, este continua a ser somente um transmissor de conhecimento. Nesse sentido, além de não mediar as relações aluno-vídeo/internet, também não contribui para a formação de um aluno-espectador crítico.

Diante disso, vale colocar que Fantin (2006) afirma que é importante que o professor não seja passivo perante as mídias, para que então 
as possa trabalhar de forma ativa com seus alunos (despertando neles a crítica e a discussão sobre as mídias também). Ao fazer a mediação entre as mídias e os alunos e ao agir de forma crítica sobre a mediação das mídias, o professor pode estar realmente aproveitando as potencialidades que elas oferecem. Possibilidades que vão além de simples ilustração e que podem mediar discussões, críticas e questionamentos ricos para o trabalho da "mídia para educação" em sala de aula.

No decorrer da análise dos depoimentos e das observações sobre as mediações, foi possível verificar que a maioria dos professores atribuiu papel importante à questão das mediações a partir das mídias, mas, durante seus trabalhos, conduziram atividades de maneira contrária ao que afirmaram. Os professores utilizaram as mídias como recurso ilustrativo aos conteúdos que trabalhavam, servindo apenas como complemento às atividades, sem gerar discussões e questionamentos, prejudicando as possibilidades de mediações com o uso das mídias.

\section{CONSIDERAC̣ÕES FINAIS}

As políticas governamentais de modernização das escolas públicas, tanto em proporções nacionais quanto municipais, levam às escolas diversas mídias audiovisuais, seja com a construção de laboratórios de informática com internet, com o envio de acervo educativo em vídeo (com equipamentos para reprodução) ou com a criação de canais de televisão voltados para a educação. As escolas, portanto, em sua maioria, já possuem equipamentos para trabalhar com diversos formatos de mídia. Afirma Napolitano (2003) que a maioria das escolas tem, no mínimo, um aparelho de televisão e um videocassete.

Além de modernizar as escolas públicas, essas políticas, em seus projetos, incluem também a formação e a capacitação dos professores para o trabalho com as mídias por meio de cursos e formação em serviço oferecidos tanto pelas Secretarias de Educação quanto pelo Ministério da Educação.

A partir dessa conjuntura, o presente artigo teve como objetivo geral analisar como os professores estão utilizando as mídias audiovisuais em sala de aula. A partir desse objetivo geral foram traçadas duas questões: (a) como os professores utilizam as mídias audiovisuais em sala de 
aula? Em que situação? Com que finalidade? e (b) de que maneira as mediações ocorrem a partir do uso de mídias em sala de aula.

O referencial teórico abordou questões relacionadas a dois pontos principais. O primeiro refere-se às relações entre mediações, mídias e mídia-educação e o segundo ponto trata das mídias e seus usos em salas de aula.

A análise dos dados coletados foi feita através da análise temática de Bardin (2003). A partir dela emergiram diversos temas e subtemas abordados pelos professores em suas respostas. Esses temas e subtemas foram analisados à luz dos referenciais teóricos apresentados e também cruzados com os dados da caracterização do campo e dos professores. A partir dessas análises foram constatados pontos interessantes que clarificam o objetivo geral e as questões apresentadas neste trabalho, que também vão além deles.

Em relação à primeira questão verificou-se que os professores utilizam as mídias de formas diversas, envolvendo diferentes situações e finalidades. Por meio dos dados do questionário, evidenciou-se que a maioria dos professores considera importante o uso da mídia em sala de aula. Entre os que consideram importante o uso das mídias, e que responderam à entrevista, a maioria atribui a importância da mídia tanto ao fato de ela aproximar o aluno da realidade quanto de servir como nova linguagem para o trabalho em sala de aula.

O uso da mídia em sala de aula que mais predominou foi a utilização como ilustração, tanto na utilização do vídeo quanto da internet. Nesse tipo de abordagem, a mídia é usada para exemplificar determinados pontos de um conteúdo trabalhado.

No caso específico do vídeo, nos dados apresentados foi observado que vários professores utilizavam-se dele também apenas como ilustração, sem trazer novas discussões e posicionamentos para a sala de aula. Enquanto poucos professores, apesar de usarem o vídeo só como recurso ilustrativo, aproveitaram-se do conteúdo trazido por ele para estimular discussões e críticas com seus alunos, vendo o conteúdo ilustrado no vídeo como um estímulo a abordagens de diferentes pontos de um conteúdo.

No caso específico da internet, usada conforme citado anteriormente, alguns professores levavam os alunos para o laboratório de informática para realizar pesquisas nos sites sem discutir os conteúdos que 
estavam pesquisando e, ainda, os colocavam para copiar os textos dos sites. Em sala de aula, pouco se remetiam ao pesquisado. Porém, outros poucos professores trabalharam a internet como ilustrativa, mas levaram os conteúdos pesquisados para as salas de aula e daí estabeleceram discussões interessantes com os alunos.

É válido citar que as mídias (Internet/vídeo) também foram usadas como sensibilização, partindo-se do apresentado na mídia para a discussão em sala de aula e permeando a temática da mídia por todo o processo de trabalho de um conteúdo. Também em alguns casos foi observada a utilização da mídia como texto-gerador e motivador de análise de conjunto de um conteúdo, com a presença da temática da mídia por todo o processo, e também analisando o processo de construção da própria mídia, além do uso como construção cooperativa, principalmente relativa à internet, por meio da qual o professor só dizia o tema e os alunos construíram juntos conceitos, a partir de pesquisas na internet. Porém esses usos foram poucos se comparados com a forma de uso ilustrativo da mídia.

Em relação às situações e finalidades em que os professores utilizaram-se das mídias, os dados também apresentaram informações heterogêneas. Alguns professores utilizavam as mídias no início de um conteúdo, outros, durante a aplicação do mesmo e, outros, ao final de um conteúdo. É interessante notar que tanto os professores que trabalharam a mídia somente de forma ilustrativa (sem utilizar todas as suas potencialidades) quanto que exploraram as diversas possibilidades das mídias utilizaram-nas nos mais diversos momentos. Ficou evidenciado, no decorrer das observações, então, que não é a ordem que interfere no desempenho de um trabalho com uma mídia, mas sim o modo como esse trabalho é feito e de que maneira o professor estimula seus alunos e estes são sensibilizados pela mídia utilizada em sala de aula.

Assim, de modo geral, foi observado que um número significativo dos professores lida com a mídia a partir de uma perspectiva ilustrativa. Não a veem e nem a utilizam de forma mais articulada com os conteúdos, mas, sim, como complemento do trabalho, fazendo de certa forma o subaproveitamento das potencialidades das mídias.

A segunda questão proposta refere-se às possibilidades de mediações com os trabalhos com mídias em sala de aula. A análise dos dados obtidos teve como referencial os tipos de mediações escolares 
apontadas por Orozco (1991): mediação institucional, individual, situacional e vídeo-tecnológica.

A partir dos dados obtidos pode ser observado que a maioria dos professores considera que a presença das mídias em sala de aula promove mediações nas relações professor-aluno e aluno-conteúdo, e que, portanto, enriquece o diálogo em sala de aula. Porém, na análise dos diários de campo, nota-se que o trabalho de muitos professores não corresponde à opinião que possuem sobre as mediações a partir das mídias.

Tendo em vista a confluência de dados, concluiu-se que, no trabalho da maioria dos professores, prevalece apenas a mediação institucional (relação professor-alunos) e um pouco da mediação vídeo-tecnológica (mídias-alunos), ou seja, em seus trabalhos com as mídias não houve a busca de diálogo com seus alunos (mediação individual, aluno com sua opinião) e nem o estímulo à mediação situacional (discussões entre os alunos em sala e fora dela). Foi observado que os professores que realizaram esse trabalho foram os mesmos que utilizaram a mídia como ilustrativa, não buscando discussões e questionamentos a partir delas. Já os professores que fizeram uso mais aprofundado da mídia apresentaram todos os quatro tipos de mediações escolares, pois promoveram discussões, ouvindo a opinião dos alunos (mediação individual), e estimularam discussões entre eles (mediação situacional), além das mediações de caráter institucional e vídeo-tecnológica, ao utilizarem-se da mídia como ponto de partida para guiar os conteúdos a serem trabalhados.

Portanto, conclui-se que as possibilidades de mediações a partir das mídias são muitas, mas dependem de como o professor lida com elas em sala de aula. Se tratá-las sem explorar suas diversas potencialidades e sem usá-las como objetos de discussão não estarão conduzindo as mediações em uma teia, como aponta Martín-Barbero (2003), e, assim, não estarão aproveitando as diversas possibilidades de mediações com o do uso das mídias.

Outros pontos surgiram a partir dos dados coletados nas escolas, que estão diretamente ligados às formas de uso da mídia em sala de aula, são referentes às dificuldades encontradas pelos professores na utilização dessas mídias. Essas dificuldades abrangem desde questões de infraestrutura até questões de características e formação dos professores perante as mídias.

Com relação à infraestrutura, pode-se concluir que todas as escolas estão equipadas, mas que a manutenção dos equipamentos não 
está sendo feita periodicamente. Também a quantidade de equipamentos é pequena para atender grande quantidade de alunos por sala, tanto no laboratório de informática (somente dez computadores) quanto na sala de vídeo (televisão pequena). Também os sistemas de agendamentos dos equipamentos, principalmente dos laboratórios de informática, não se efetiva com controle rigoroso. Esses pontos foram levantados pelos professores como desmotivadores do uso das mídias.

Referente ao laboratório de informática, os professores levantaram a necessidade de se ter um professor de laboratório de informática, similar ao professor regente de sala de leitura. Segundo os professores, esse profissional poderia auxiliar na realização de atividades na informática, na proposição de novos trabalhos e no controle do uso do laboratório.

No que diz respeito às características dos professores, especificamente à carga horária de trabalho, conclui-se que a maioria dos professores possui carga horária semanal elevada e que esta também é uma justificativa dos mesmos com relação a uma não periodicidade de trabalhos com mídias, pois, segundo um número expressivo de participantes, não há tempo suficiente para preparar as atividades com as tecnologias. A carga horária também é uma das justificativas pela maioria não ter feito ou não se interessar em fazer os cursos de capacitação oferecidos para o trabalho com mídias em sala de aula pela SME-RJ e NTE.

Diante das falas dos professores, observa-se que o uso das mídias nas escolas investigadas ainda é precário em relação às diversas possibilidades que as inovações tecnológicas oferecem para o trabalho em sala de aula. Chama-se de "ainda precário" porque as iniciativas de modernização das escolas e capacitação dos professores existem já há algum tempo, o que confirma a afirmação de Martín-Barbero (2003) de que as tecnologias da informação presentes na escola deixam ainda mais visíveis as brechas entre a cultura a partir da qual os professores ensinam e aquela em que os alunos aprendem.

Porém, conclui-se também que esse "ainda precário" é um problema de múltiplas dimensões, que permeia o conteúdo das políticas públicas e suas formas de implantação e a própria estruturação do cotidiano escolar, ou seja, o problema não está só na política e nem só nos professores.

As considerações finais obtidas nesta pesquisa apontam para algumas possíveis saídas que podem ser pensadas para contribuir para o 
melhor aproveitamento das mídias pelas escolas, saídas apontadas nos próprios depoimentos dos professores, entre as quais a possibilidade de criação do professor de laboratório de informática, similar ao professor regente de sala de leitura, além da questão do excesso de carga horária que atrapalha os professores na preparação de atividades e nas capacitações para o trabalho com mídia.

Por fim, cabe afirmar que as possibilidades de uso e mediações das mídias em salas de aula são muitas, mas apontam para formas de uso que não privilegiam todas as potencialidades que as mídias têm a oferecer, o que advém de diversos fatores tais como a infraestrutura das escolas, a formação dos professores e as próprias políticas públicas referentes à modernização.

Finaliza-se este artigo apontando a importância de se aprofundar os estudos referentes às possibilidades de uso e mediações das mídias dentro das escolas, no contexto de uma análise que perpasse questões pedagógicas e políticas, a fim de contribuir para o melhor aproveitamento educacional dos recursos investidos em mídias nas escolas. 


\section{REFERÊNCIAS}

ALVES-MAZZOTTI, A.; GEWANDSZNAJDER, F. O método nas ciências naturais e sociais: pesquisa quantitativa e qualitativa. São Paulo: Pioneira, 2000.

BARDIN, L. Análise de conteúdo. Lisboa: Edições 70, 2003.

BELLONI, M. L. O que é mídia-educação. Campinas, SP: Autores Associados, 2005.

BOGDAN, R. E BIKLEN, F. Investigação qualitativa em educação. Porto: Porto Editora, 1994.

FANTIN, M. Mídia-educação: conceitos, experiências, diálogos Brasil-Itália. Florianópolis: Cidade Futura, 2006.

HARGREAVES, A. O ensino na sociedade do conbecimento: educação na era da insegurança. Porto Alegre: ArtMed, 2004.

KENSKI, V. Tecnologias e ensino presencial e a distância. Campinas, SP: Papirus, 2003.

MARTÍN-BARBERO, J. Globalização comunicacional e transformação cultural. In:

MORAES, de D. (Org.). Por uma outra comunicação: Mídia, mundialização cultural e poder.

2 ed. Rio de Janeiro: Record, 2004. p. 57-86.

MARTÍN-BARBERO, J. Dos meios às mediações - Comunicação, cultura e hegemonia. Rio de Janeiro: Editora da UFRJ, 2003.

BRASIL. Ministério da Educação. Textos explicativos e informativos do funcionamento dos programas de modernização das escolas públicas brasileiras, [2009].

Disponível em: <http://portal.mec.gov.br/index.php>. Acesso em: 30 jan. 2009.

MORAN, J. Como utilizar as tecnologias na escola. In: A educação que desejamos: Novos desafios e como chegar lá. São Paulo: Papirus, 2007. p. 101-111

MORAN, J. Ensino e aprendizagem inovadores com tecnologias audiovisuais telemáticas. In: MORAN, J; MASETTO, M; BEHRENS, M. Novas tecnologias e mediação pedagógica. Campinas, SP: Papirus, 2000.

MULTIRIO. Empresa Municipal de Multimeios do Rio de Janeiro. Textos explicativos e informativos do funcionamento desta empresa. Disponível em:

<http://www.multirio.rj.gov.br/portal/>. Acesso em 30 jan. 2009.

NAPOLITANO, M. Como usar o cinema em sala de aula. São Paulo: Contexto, 2003.

OROZCO, G. Mediações escolares e familiares na recepção televisiva. Revista Brasileira de Comunicação. São Paulo, INTERCOM, 1991.

PREFEITURA MUNICIPAL DO RIO DE JANEIRO. Secretaria Municipal de Educação. Textos explicativos e informativos do funcionamento dos programas de modernização das escolas municipais, [2009]. Disponível em <http://www.rio.rj.gov.br/sme/>. Acesso em: 30 jan. 2009.

PRETTO, N. L. Uma escola sem/ com futuro. Campinas, SP: Papirus, 1996.

PRIMO, Alex. Avaliação em processos de educação problematizadora online. In: Marco Silva, Edméa Santos. (Org.) Avaliação da aprendizagem em educação on-line. São Paulo: Loyola, 2006. p. 38-39.

ROMERO, T. Aprendizagem significativa em um ambiente multimídia, 2006. Disponível em: <http://www.rived.mec.gov.br/artigos/2006-VEIAS.pdf>. Acesso em: 15 jan. 2008.

VALENTE, J.A. Uso da internet em sala de aula. Educar em Revista, [S.1.], v. 19, p. 131 146, 2002. Disponível em:

http://ojs.c3sl.ufpr.br/ojs2/index.php/educar/article/view/2086/1738>. Acesso em: 14 jul. 2008. 


\section{NOTAS}

1 Nesta pesquisa, que é resultante de uma dissertação de mestrado, o termo novas mídias audiovisuais, tanto quanto somente mídias audiovisuais, mídias, novas tecnologias, tecnologias e Tecnologias de Informação e Comunicação (TIC), abrangem o que se refere à internet, à televisão, ao vídeo/dvd. Referenciando-se na definição de Belloni (2005, p. 21), "as TIC são o resultado da fusão de três grandes vertentes técnicas: a informática, as telecomunicações e as mídias eletrônicas".

2 A mediação trata da relação e intervenção humana em processos de produção e circulação de formas simbólicas. Constitui a relação entre mídias e seres humanos, de forma dialética (OROFINO, 2005) 